\title{
Synthesis of Lithium Peroxide from Hydrogen Peroxide and Lithium Hydroxide in Aqueous-Organic Medium: Wasteless Technology
}

\author{
Roman Nefedov* and Yury Ferapontov \\ Tambov State Technical University, Tambov, Russia
}

\begin{abstract}
Lithium is a rare element, and widely used in manufacturing, electronics, medicine, and etc. One of the important lithium compounds is lithium peroxide. It is a component of regenerating products to protect the human respiratory system from damaging factors of chemical and biological nature. This paper describes the methods of obtaining the lithium peroxide. All industrial techniques for the synthesis of lithium peroxide are presented. A critical assessment of these techniques is given. A new wasteless synthesis technology of lithium peroxide from Hydrogen Peroxide and Lithium Hydroxide in Aqueous-Organic Medium is presented. This technology allows obtaining the pure product containing $\mathrm{Li}_{2} \mathrm{O}_{2}$ up to $94 \%$. The possibility of the solvent regeneration by the anhydrous lithium hydroxide has been shown. The yield of the lithium $-98 \%$ and a significant reduction in solvent consumption per unit of finished product has been obtained.
\end{abstract}

\section{Introduction}

The inorganic peroxide compounds based on rare, radioactive, and especially alkali metals have a wide range of industrial applications (e.g., energy storage and oxygen source, etc.) [1,2].

An identifying characteristic of inorganic peroxide compounds is the ability to produce oxygen in the active form by reaction with carbon dioxide and noxious impurities (human body waste products). That is why they are widely used in life-support systems (LSS), i.e. where a person is forced to stay and work in submarines, shelters, spaceships cabin that are isolated from the environment [4-6]. As a result, the development of new environmentally friendly technologies to obtain peroxide compounds of high purity on an industrial scale is a challenge by the present day. One of these compounds is lithium peroxide, which wasteless technology is described in this work.

There are a number of methods for producing lithium peroxide, each of which has its advantages and disadvantages. For example, lithium peroxide $\left(\mathrm{Li}_{2} \mathrm{O}_{2}\right)$ was obtained in the early 20th century by Forkran [7] by the following method: aqueous-alcoholic solution containing $300 \mathrm{~mL}$ of $12 \% \mathrm{H}_{2} \mathrm{O}_{2}$ and $450 \mathrm{~mL}$ of ethanol was added to $100 \mathrm{~mL}$ solution of lithium hydrooxide containing $6.31 \mathrm{~g} \mathrm{LiOH}$. The resulting precipitate was dried for a long time over phosphorus pentoxide. The yield of a peroxide compound was $9 \mathrm{~g}$ or $72 \%$ based on $\mathrm{Li}_{2} \mathrm{O}_{2}$. Under laboratory conditions a product containing $99.6 \% \mathrm{Li}_{2} \mathrm{O}_{2}$ [8] is obtained. The synthesis method $\mathrm{Li}_{2} \mathrm{O}_{2}$ proposed by Forkran has not undergone significant change by present day.
The use of ethanol is not a prerequisite for obtaining lithium peroxide, although it is beneficial in terms of that lithium peroxide contained in it unlike other organic substances practically insoluble (dissolved in methanol about $3.5 \mathrm{~g} / \mathrm{L} \mathrm{Li}_{2} \mathrm{O}_{2}$. Ethanol can be replaced by other organic solvents (methanol, pyridine, propanol, kenotic and others $[12,14])$. One suggests considering the basic methods for the synthesis of hydrogen peroxide, lithium peroxide and lithium hydroxide with the use of organic solvents.

T.A. Dobrynina and S.Z. Makarov using the data on the solubility in the ternary system $\mathrm{LiOH}-\mathrm{H}_{2} \mathrm{O}_{2}-\mathrm{H}_{2} \mathrm{O}$ and thermal stability of peroxohydrates and lithium peroxide hydrate $[9,10]$ developed two methods of synthesis of lithium peroxide, which were then implemented on the industrial scale [11, 12]. The study results of the thermal stability $\mathrm{Li}_{2} \mathrm{O}_{2} \cdot 2 \mathrm{H}_{2} \mathrm{O} \cdot \mathrm{H}_{2} \mathrm{O}_{2}$ and $\mathrm{Li}_{2} \mathrm{O}_{2} \cdot \mathrm{H}_{2} \mathrm{O}$ demonstrated that these compounds in $85-$ $100{ }^{\circ} \mathrm{C}$ can be easily decomposed to lithium peroxide. According to this, depending on the synthesis conditions, the process may run as the following equations of reactions:

$$
\begin{array}{r}
2 \mathrm{LiOH}+2 \mathrm{H}_{2} \mathrm{O}_{2} \rightarrow \mathrm{Li}_{2} \mathrm{O}_{2} \cdot \mathrm{H}_{2} \mathrm{O}_{2} \cdot 2 \mathrm{H}_{2} \mathrm{O} \\
\mathrm{Li}_{2} \mathrm{O}_{2} \cdot \mathrm{H}_{2} \mathrm{O}_{2} \cdot 2 \mathrm{H}_{2} \mathrm{O} \rightarrow \mathrm{Li}_{2} \mathrm{O}_{2}+3 \mathrm{H}_{2} \mathrm{O}+0.5 \mathrm{O}_{2} \\
2 \mathrm{LiOH}+\mathrm{H}_{2} \mathrm{O}_{2} \rightarrow \mathrm{Li}_{2} \mathrm{O}_{2} \cdot \mathrm{H}_{2} \mathrm{O}+\mathrm{H}_{2} \mathrm{O} \\
\mathrm{Li}_{2} \mathrm{O}_{2} \cdot \mathrm{H}_{2} \mathrm{O} \rightarrow \mathrm{Li}_{2} \mathrm{O}_{2}+\mathrm{H}_{2} \mathrm{O}
\end{array}
$$

Since the solubility of dehydrate peroxohydrate of lithium peroxide $\left(\mathrm{Li}_{2} \mathrm{O}_{2} \cdot \mathrm{H}_{2} \mathrm{O}_{2} \cdot 2 \mathrm{H}_{2} \mathrm{O}\right)$ in aqueous solutions of hydrogen peroxide is $5-7 \%$ based on the $\mathrm{Li}_{2} \mathrm{O}$ as salting out agent in both cases, ethanol was used.

Synthesis of $\mathrm{Li}_{2} \mathrm{O}_{2} \cdot \mathrm{H}_{2} \mathrm{O}_{2} \cdot 2 \mathrm{H}_{2} \mathrm{O}$ was conducted by dissolving lithium hydroxide monohydrate under icecooling in $65-67 \%$ hydrogen peroxide. The resulting

*Corresponding author: kliorik@mail.ru 
mixture was poured under continuous agitation into the ethanol, cooled to $0^{0} \mathrm{C}$. At the same time the formation of a white crystalline precipitate $\mathrm{Li}_{2} \mathrm{O}_{2} \cdot \mathrm{H}_{2} \mathrm{O}_{2} \cdot 2 \mathrm{H}_{2} \mathrm{O}$ was observed. The starting materials were taken in the molar relation of $\mathrm{H}_{2} \mathrm{O}_{2} / \mathrm{LiOH}=3.9 / 1$. The resulting precipitate was separated from the mother solution by filtration, washed with absolute ethanol, dried in vacuum at $100 \mathrm{~Pa}$. The yield based on lithium was $80-85 \%$. The final product contained $92-94 \%$ of lithium hydroxide.

Preparation of the second lithium peroxide method carried out as follows. A suspension of lithium hydroxide in ethanol with vigorous stirring was brought to boil with $28 \%$ hydrogen peroxide solution added after. The molar ratio of the components in the reaction mixture was $\mathrm{H}_{2} \mathrm{O}_{2} / \mathrm{LiOH}=(0.75-1) / 1$. The mixture was stirred under the boil for 1.2 hours. The resulting precipitate monohydrate lithium peroxide of a pale cream colour was separated from the mother liquor by filtration, washed with absolute ethanol and dried under vacuum at $80-120{ }^{\circ} \mathrm{C}$. The yield on the lithium was 80 $85 \%$. The final product contained $90 \%$ of lithium peroxide.

In $\mathrm{Li}_{2} \mathrm{O}_{2}$ synthesis methods described above, there are two significant disadvantages - low yield for lithium and a high solvent consumption per unit of finished product. The reason for it is that the filtrate and the washing solution together are hard-separable mixture of water, solvent and lithium compound. That is why this mixture is removed from the process as waste. Thus, in the methods [12-14] about $15-20 \%$ of the initial lithium compounds and all solvent are thrown out into the environment. It is not only environmentally harmful, but also unprofitable. Reuse of the solvent in the process can be held only by separating it from the water.

In patent [15] a method of lithium peroxide production with the help of n-propyl or isopropyl alcohol is described. A saturated aqueous solution of lithium hydroxide is prepared and then the required amount of $30 \%$ hydrogen peroxide is added thereto. Obtained solution is cooled to $20{ }^{0} \mathrm{C}$ and n-propyl spirit is added with stirring. Thus, a compound of $\mathrm{Li}_{2} \mathrm{O}_{2} \cdot \mathrm{H}_{2} \mathrm{O}_{2} \cdot 2 \mathrm{H}_{2} \mathrm{O}$ is obtained which is separated from the mother solution by filtration and dried in vacuum. For reuse (regeneration) of the solvent precipitation from filtrate of lithium as carbonate is carried out by the injection in filtrate anhydrous potassium carbonate. Precipitated lithium carbonate is separated from the filtrate and the solvent is returned to the stage of the reaction of lithium hydroxide and hydrogen peroxide.

However, the injection of potassium carbonate in the filtrate leads to accumulation therein of ions of potassium and carbonate - anions, which leads to contamination of the final product - lithium peroxide by these ions and hence reduces the mass fraction of a base substance. In addition, since the filtrate contains excess water that cannot be completely removed by the injection of potassium carbonate, returned to a cycle solvent also contains water which leads firstly to forming of a precipitate of peroxide lithium compound containing a large amount of water and secondly adding of extra quantity of anhydrous solvent is required in order to intensify the withdrawal of water from the reaction zone. In addition, the filtrate contains water excess, which cannot be completely removed by the introduction of potassium carbonate. The recycled solvent also contains the water. In the result, a precipitate of lithium peroxide containing a lot of water. For the intensifying the withdrawal of water from the reaction zone, an addition of further anhydrous solvent is needed. The lithium carbonate, formed from the filtrate processing, cannot be returned to the production cycle without further processing into the lithium hydroxide, and it is removed as a waste. As a result, from cycle to cycle, a most expensive component (the lithium) is lost during synthesis.

Hence, though this method reduces the consumption of dissolvent by bringing it back to the cycle, it does not provide a sufficiently high yield of lithium and thus it is inefficient. Industrial processes for obtaining lithium peroxide are known where the organic solvents are not used completely or only in the final stages of chemicaltechnological process. The "Lithium Corp. of America" company developed several options for the lithium peroxide of industrial production $[16,17]$.

Lithium peroxide can be received in ample quantity through lithium alkoxides as well, because the solubility of lithium methoxide in methanol is $90 \mathrm{~g} / \mathrm{L}$ [12].

These methods along with ones mentioned above have a significant disadvantage-low yield of lithium (under 85\%).

Other methods of preparing lithium peroxide - the oxidation of metallic lithium by oxygen, hydroxide, oxide and lithium amalgam $[12,17]$, the reaction of lithium nitrate with sodium superoxide in liquid ammonia [17] are not of interest for the development of new industrial technologies, leading to the formation of products containing $30-75 \% \quad \mathrm{Li}_{2} \mathrm{O}_{2}$ or they remain laboratory methods [18].

Thus, the development of a new obtaining industrial technologies peroxide compounds of high purity is a challenge. Current study develops a cost- and resourceeffective, wasteless synthesis technology of Lithium Peroxide.

\section{Methods and Materials}

Developed environmentally friendly technology for producing lithium peroxide of lithium hydroxide and hydrogen peroxide in-ethanol in the environment is implemented in process flow diagram (Fig. 1) and includes the following technological stages and operations.

The reactor 5 from the measuring device 1 received a certain amount of ethanol and lithium hydroxide monohydrate from the feeder 3 , where they were mixed by a mechanical stirrer. The obtained reaction mixture was heated to boiling direct steam entering the reactor casing 1. After that the temperature in the reaction zone was reduced to $75{ }^{\circ} \mathrm{C}$

This method by the increase of the center of crystallization allows receiving a finer and consequently more reactive product, which is essential for its 
subsequent use in LSS systems. Ethanol vapors were entrapped in the reflux condenser 4 and returned back to the reactor 1 . Then, $30 \%$ hydrogen peroxide was added from the measuring device 2 . The temperature in the reaction zone was monitored by a contact thermocouple and maintained at a constant level..

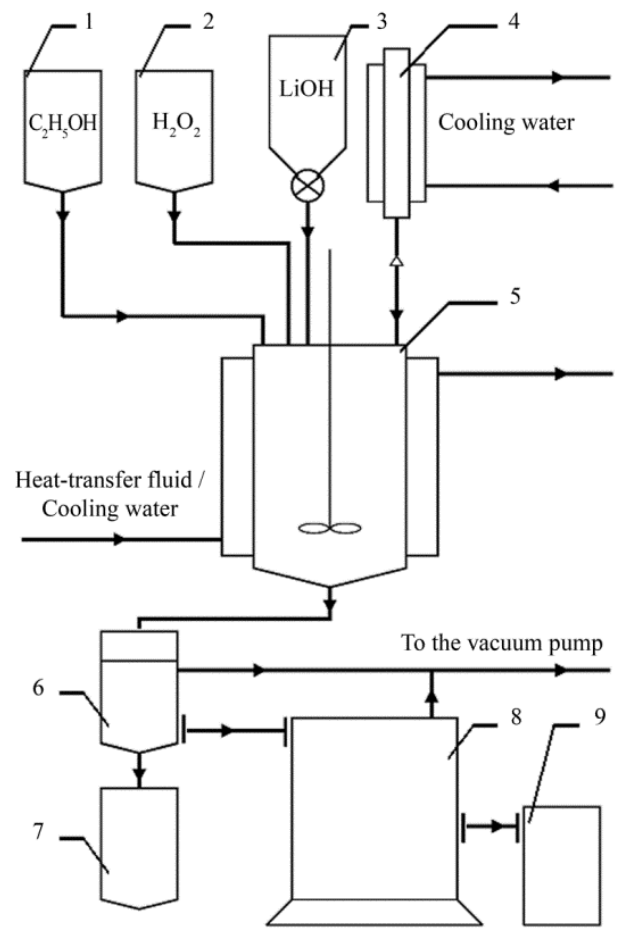

Fig. 1. Technological scheme of receiving peroxide of lithium: 1,2 - measuring tanks, 3 - star feeder, 4 - reflux condenser, 5 - reactor, 6 - suction filter, 7 - capacity, 8 vacuum drying cabinet, 9 - container.

The precipitate formed $\mathrm{Li}_{2} \mathrm{O}_{2} \cdot \mathrm{H}_{2} \mathrm{O}_{2} \cdot 2 \mathrm{H}_{2} \mathrm{O}$ was filtered at suction-filter 6, washed with two portions of ethanol. After that it was dried in a vacuum oven 8 for $30-40$ minutes at a temperature of 35 to $40{ }^{0} \mathrm{C}$ on griddles, made of stainless steel. Then, the temperature was increased to $125-135^{\circ} \mathrm{C}$ and the product was dried for $8-$ $9 \mathrm{~h}$. The residual pressure in the vacuum-oven was $4.5 \mathrm{kPa}$. The finished product was collected in a container 9 .

\section{Results and discussion}

X-ray phase analysis (XRD) of the lithium peroxide samples has been carried out. Radiographs of the samples were recorded on a DRON-6 with the filtered $\mathrm{Cu}$ Ka- radiation $(1=0.154051 \mathrm{~nm})$. Data with XRD results and calculated based on diffraction patterns values of interplanar distance $\left(\mathrm{A}^{\circ}\right)$ are shown in Fig. 2. $\mathrm{XRD}$ data, as well as the results of chemical analysis of these samples showed no water in their composition. So, dehydration process runs fully under conditions of experiments.

The composition of the resulting precipitate $\left(\mathrm{Li}_{2} \mathrm{O}_{2} \cdot \mathrm{H}_{2} \mathrm{O}_{2} \cdot 2 \mathrm{H}_{2} \mathrm{O}\right)$ was determined by chemical analysis and DTA method. The obtained data indicates that in the described conditions the reaction route between the hydrogen peroxide and lithium hydroxide-guide is expressed by equation 1 . Lithium yield was $91 \%$, the final product contained $93.4 \%$ of lithium peroxide.

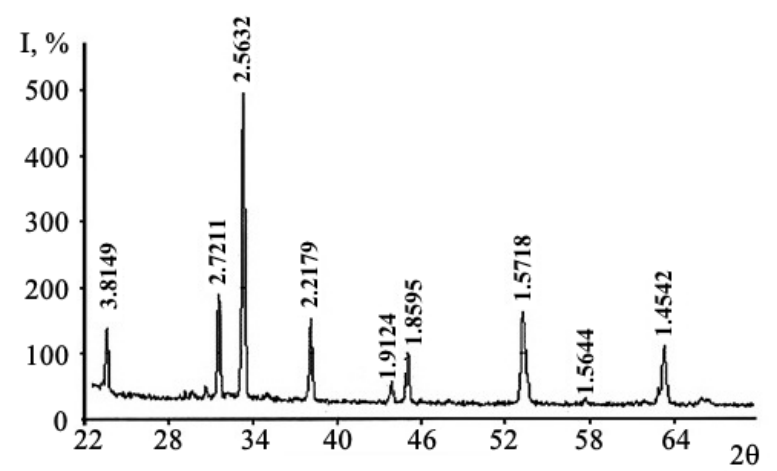

Fig. 2. The diffraction pattern of the sample obtained peroxide lithium.

In order to use ethanol in the next cycle, in the mother solution collected in container 7 , the amount of anhydrous lithium hydroxide calculated according to the equation of reaction (5) was added, which reacts with water to form lithium hydroxide monohydrate.

$$
\mathrm{LiOH}+\mathrm{H}_{2} \mathrm{O} \rightarrow \mathrm{LiOH} \cdot \mathrm{H}_{2} \mathrm{O} \downarrow
$$

The precipitate $\mathrm{LiOH} \cdot \mathrm{H}_{2} \mathrm{O}$ was filtered on a suctionfilter 6 and processed its dehydration in a vacuum oven at a temperature of $150-170{ }^{\circ} \mathrm{C}$. After dehydration anhydrous lithium hydroxide weight (taking into account technological and logical losses) was not changed. The missing amount of ethanol was added to solvent remaining after regeneration, and returned to the first stage of the process in the reactor 1 , so the regenerated solvent was mixed with a new portion of the monohydrate of lithium hydroxide and subsequent operations were carried out to obtain lithium peroxide. The yield on the lithium increased to $98 \%$. The final product contained $93.4 \%$ of lithium peroxide.

There is main advantage using of the mother solution of anhydrous lithium hydroxide for regeneration: secondary ions are not entered into mother solution. It means the absence of contamination of the desired product. To identify the optimal conditions of this process, a series of experiments with different ratios of the reactants and temperature were carried out. All data are presented in Table 1.

The data in Table 1 shows that the process is best performed at a molar ratio of the starting components $\mathrm{LiOH} / \mathrm{H}_{2} \mathrm{O}_{2}=1 /(1.10-1.15)$. In this case, a final product with a maximum content of basic substance is received. Further increase (as well as decrease) the amount of added hydrogen peroxide does not increase the content of the basic substance in the product synthesis. The preferred temperature of the process flow is $75{ }^{0} \mathrm{C}$. Reducing the temperature in the reaction zone also reduces the basic substance in the product synthesis. Using lithium hydroxide for regeneration of solvent allows reducing consumption of ethanol for 5 cycles 67.5 liters to 2.5 liters in the preparation of $3.3 \mathrm{~kg}$ of lithium peroxide and thus increasing the yield of lithium 
from $91.5 \%$ to $96.7 \%$ without deteriorating the quality of the product.

Table 1. The data of experiments on identification of optimum conditions. $\mathrm{T},{ }^{0} \mathrm{C}$ - temperature in a reaction zone; $\mathrm{H}_{2} \mathrm{O}_{2}(\mathrm{~g}) /$ $\mathrm{LiOH}(\mathrm{g}) / \mathrm{EtOH}(\mathrm{L})$ - the cconsumption of reagents for 5 cycles; $\mathrm{m}, \mathrm{g}$ - the amount of peroxide of lithium received for 5 cycles; $\alpha, \%$-the yield on lithium for 5 cycles; $\omega, \%$ - mass fraction of the main substance.

\begin{tabular}{|l|c|c|c|c|c|c|}
\hline No & $\begin{array}{c}\text { Molar ratio } \\
\mathbf{L i O H} / \mathbf{H}_{2} \mathbf{O}_{2}\end{array}$ & $\mathbf{T},{ }^{\mathbf{0}} \mathbf{C}$ & $\begin{array}{c}\mathbf{H}_{\mathbf{2}} \mathbf{O}_{\mathbf{2}} \mathbf{( g )} \\
\mathbf{L i O H}(\mathbf{g}) \\
\mathbf{E t O H} \\
\mathbf{( L )}\end{array}$ & $\mathbf{m , g}$ & $\begin{array}{c}\boldsymbol{\alpha}, \\
\mathbf{\%}\end{array}$ & $\begin{array}{c}\boldsymbol{\mathbf { \omega }} \\
\mathbf{\%}\end{array}$ \\
\hline 1 & $1 / 1.10$ & 75 & $\begin{array}{c}5565.1 \\
3571.5 \\
2.5\end{array}$ & 3306.1 & 96.6 & 93.4 \\
\hline 2 & $1 / 1.15$ & 75 & $\begin{array}{c}5818.1 \\
3571.5 \\
2.5\end{array}$ & 3309.5 & 96.7 & 94,0 \\
\hline 3 & $1 / 1.20$ & 75 & $\begin{array}{c}6071 \\
3571.5 \\
2.5\end{array}$ & 3306.1 & 96.6 & 93.4 \\
\hline 4 & 1 & 75 & $\begin{array}{c}5059.2 \\
3571.5 \\
2.5\end{array}$ & 3280.8 & 95.8 & 86.0 \\
\hline 5 & $1 / 1.10$ & 75 & $\begin{array}{c}5565.1 \\
3571.5 \\
2.5\end{array}$ & 3312.9 & 96.8 & 94.0 \\
\hline 6 & $1 / 1.15$ & 70 & $\begin{array}{c}5818.1 \\
3571.5 \\
2.5\end{array}$ & 3281.4 & 95.9 & 88.2 \\
\hline 7 & $1 / 1.15$ & 75 & $\begin{array}{c}5818.1 \\
3571.5 \\
67.5\end{array}$ & 3131.5 & 91.5 & 94.0 \\
\hline
\end{tabular}

NOTE. The amount of consumable hydrogen peroxide $\left(\mathrm{H}_{2} \mathrm{O}\right)$ is given in terms of $100 \%$ substance. The amount of consumable lithium hydroxide monohydrate $\left(\mathrm{LiOH} \cdot \mathrm{H}_{2} \mathrm{O}\right)$ is given in terms of anhydrous lithium hydroxide ( $\mathrm{LiOH})$. The following table shows the results of obtaining lithium peroxide for 5 cycles. In this case, one cycle is 0.5 liters of solvent consumption and for five cycles - 2.5 liters, while the solvent-free regeneration (Example 7) solvent consumption for the same five cycles was $67.5 \mathrm{~L}$.

\section{Conclusion}

A new environmentally friendly synthesis technology of lithium peroxide is presented. The technology is based on interaction of hydrogen peroxide solution with a hydroxide of lithium in ethanol followed by vacuum thermal dehydration of the intermediate adduct dehydrate peroxohydrate peroxide lithium $\left(\mathrm{Li}_{2} \mathrm{O}_{2} \cdot \mathrm{H}_{2} \mathrm{O}_{2} \cdot 2 \mathrm{H}_{2} \mathrm{O}\right)$, allowing to obtain the final product containing $94 \%$ of the main substance.

To regenerate the solvent anhydrous lithium hydroxide was used which made possible to increase the yield of lithium from 91 to $98 \%$ and to reduce solvent consumption significantly per unit of final product without introducing extraneous ions into the final product.
It has been established experimentally that the optimum process conditions for interaction of the hydrogen peroxide solution with lithium hydroxide in ethanol $\mathrm{T}=75^{\circ} \mathrm{C}$, and the molar ratio of the starting reactants $\mathrm{LiOH} / \mathrm{H}_{2} \mathrm{O}_{2}=1 /(1.10-1.15)$.

Thus, the paper demonstrates, that the technology is a cost- and resource-effective. The main advantage of this technology - no waste, and it can be used on an industrial scale.

The study was performed on the expenses of a grant from the Russian Science Foundation (project \#15-19-10028).

\section{References}

1. M.D. Radin, J.F. Rodriguez, F. Tian, D.J. Siegel, J. Amer. Chem. Society 134, 2 (2012)

2. N. Deng, W. Wang, G. Yang, Y. Qiu, RSC Advances 126, 5 (2015)

3. T. Gladysheva, N.F. Gladyshev, S. I. Dvoretsky Nanocrystalline Regenerative Products. Synthesis, Properties, Application (Spectr, Moscow, 2014, in Russian)

4. J. Presti, H. Wallman, A. Petroctlli, Undersea Technol. 8, 20 (1967)

5. G.I. Voronin A.I. Polivoda, Sustenance Space Crews (Mashinostroenie, Moscow, 1967, in Russian)

6. A. Petroctlli, A. Capolesto, Aerospase Med. 31, 440 (1964)

7. Forcrand R. De. - C.r. 130, 1465 (1900)

8. G. Brauer, Guide to Inorganic Synthesis (Mir, Moscow, 1985, in Russian)

9. S.Z. Makarov, T.A. Dobrynina, News of the Academy of Sci.: Chem. Sci. 3, 411 (1955) (in Russian - Izvestya Academii Nauk SSSR OKhN).

10. S.Z. Makarov, T.A. Dobrynina, News of the Academy of Sci.: Chem. Sci. 3, 294 (1956) (in Russian - Izvestya Academii Nauk SSSR OKhN)

11. R.O. Bach, W.W. Boardman, U.S. Patent No. 3134646, (26 May 1964)

12. T.A. Dobrynina, Lithium Peroxide (Nauka, Moscow, 1964, in Russian)

13. H.H. Strater, M. Heights, U.S. Patent No. 2,962,358 (29 November 1964)

14. R.O. Bach, W.W Boardman, U.S. Patent No. 3,147,075 (1 September 1964)

15. E.L. Klebba, U.S. Patent No. 3,212,850 (19 October 1965)

16. I.I. Vol'nov, Peroxide compounds of Alkali Metals (Nauka, Moscow, 1980, in Russian)

17.P. Winternitz, U.S. Patent No. 2,488,485 (15 November 1949)

18. Yu.A. Ferapontov, S.I. Simanenkov, N.F. Gladyshev, B.V. Putin, RF Patent No. 2,193,522 (27 November 2002) 